\title{
Melanie Klein é freudiana
}

\author{
Débora Siqueira Bueno
}

O título pode soar provocativo - mas sabe-se que Melanie Klein reivindicou um reconhecimento dessa ordem por toda a vida. Klein não fez parte do grupo de analistas pioneiros que circundavam Freud e partilharam com ele da tarefa de fazer crescer e difundir "a causa”. Não chegou à psicanálise pela via acadêmica, nem por erudição científica ou filosófica. Era "uma verdadeira outsider".

Um enorme sofrimento pessoal levou-a a buscar sua própria análise. Depois passou a observar, inquietantemente, instrumentada pelo olhar psicanalítico recém-adquirido, o que a rodeava - a si mesma e a seus filhos, em primeiro lugar. Melanie Klein começou, metafórica e literalmente, em casa. Seu pensamento foi elaborado numa forja de dor, em que se amalgamaram uma grande intuição clínica, o contato direto com os processos e fenômenos do psiquismo, uma coragem em inovar e, sem dúvida, a ambição de escrever uma obra criativa que viesse a ser reconhecida. E até hoje, quase 45 anos depois de sua morte, ainda suscita reações de encantamento ou repulsa. A essa autora não se fica indiferente. 
R E V I S T A

LATINOAMERICANA

DE PSICOPATOLOGIA

F U N D A M E N TA L

ano VII, n. 4, dez/2004

O primeiro dos méritos do livro Melanie Klein. Estilo e pensamento, editado recentemente pela Escuta, é justamente o de conduzir-se com precisão e rigor nesse terreno propenso a discussões apaixonadas. Os autores o apresentam como uma introdução ao estilo e ao pensamento de Melanie Klein, efetuada por psicanalistas não alinhados a uma escola kleiniana, mas que reconhecem a enorme contribuição dessa autora para a psicanálise e a cultura. Na valiosa introdução, Elias Mallet da Rocha Barros nos adverte que o discurso ideológico assombra permanentemente as discussões psicanalíticas. E destaca a importância de estudos como este, em que o pensamento de Melanie Klein é resgatado de eventuais marcas autoritárias e conectado às questões clínicas contemporâneas. Recuperamse as verdadeiras controvérsias, o debate psicanalítico é revitalizado.

Em um texto relativamente curto - pouco mais de duzentas páginas - os autores, Elisa Maria de Ulhoa Cintra e Luis Cláudio Figueiredo, tiveram êxito tanto em abordar o essencial de uma grande obra, quanto em lançar um novo olhar sobre a mesma. O livro traz informações sucintas sobre a vida pessoal e a trajetória de Melanie Klein, situadas no contexto histórico do movimento psicanalítico. Os principais trabalhos da psicanalista são apresentados em sua cronologia, de forma a demonstrar como foram sendo construídos sistemas teóricos coerentes, e como se deu a evolução de um a outro. Alguns conceitos são discutidos mais demoradamente, sempre lado a lado com a clínica. A linguagem é agradável e o texto, claro e didático - o leitor absorto corre o risco de, sem se dar conta, surpreender-se transportado a uma sala de aula. E aí se apresenta outra das qualidades desse livro: sua simplicidade, só aparente, certamente resultado da sedimentação de um saber longamente maturado.

Melanie Klein é apresentada como a empreendedora da primeira transformação criativa do freudismo - embora tantas vezes tenha sido acusada de "antifreudiana”. O seu pensamento é marcado desde o início por uma preocupação com a hybris, com o excesso e a insaciabilidade do desejo, com a violência pulsional. Para fundamentar teoricamente sua concepção do dinamismo psíquico, aderiu na primeira hora à dualidade pulsional proposta por Freud em 1920. A compreensão do Édipo em um plano mais metafórico e simbólico, como "uma estrutura de lugares cambiantes e uma dinâmica de inclusão-exclusão, presença-ausência", deriva da leitura atenta dos "Três ensaios sobre a teoria da sexualidade" (1905) e de "Inibição, sintoma e angústia" (1926). Onde Freud descreve a angústia relacionada ao perigo de perda do objeto, Klein intuiu a situação triangular precoce. Mas, deve-se aqui enfatizar, essa Melanie Klein freudiana é, sobretudo, revelada por Elisa Maria de Ulhoa Cintra e Luis Cláudio Figueiredo. Ao longo de todo o livro, quer seja ao discutir conceitos metapsicológicos, quer ao aproximá-los à clínica, o leitor encontra uma "tradução", em termos freudianos, do pensamento de Melanie Klein. 
O estilo - os autores ponderam que, na psicanálise, a reação ao trabalho de um autor depende muito de suas estratégias retóricas. Se Freud imprimia à sua escrita a essência mesma da experiência analítica (Mahony, 1992), se Winnicott portava uma linguagem “enganosamente simples” (Abram, 2000), que dizer do estilo de Melanie Klein? Barroco, em sua contraposição entre o bem e o mal, entre luz e sombras? Confuso, fruto da escrita numa língua estrangeira? Carente de traquejo científico e filosófico? Tudo isso é reconhecido, mas os autores vão além, ao considerar o posicionamento epistemológico da autora e o estilo de sua clínica.

A forte valorização da experiência pessoal presente no trabalho de Melanie Klein deriva em uma teorização híbrida, na qual as dimensões fenomenológica e metapsicológica se mesclam. Muitas vezes, ao teorizar sobre processos e mecanismos psíquicos arcaicos, Klein se expressa como se apenas descrevesse suas observações ou intuições clínicas, levando à confusão entre o que veio predominantemente da experiência clínica e aquilo que é hipotético, teorização sobre esta mesma experiência. Se não se distinguem esses dois planos o resultado é certo dogmatismo, uma vez que a observação seria indiscutível. Por outro lado, essa índole empirista conferiu a ela uma liberdade da qual poucos psicanalistas iniciantes poderiam desfrutar, e produziu um pensamento no qual a metapsicologia está sempre entrelaçada à clínica.

Melanie Klein é fiel à violência dos processos psíquicos. Aí residiria outra razão da resistência ao seu pensamento ao provocar um contato, de início insuportável, com o psiquismo arcaico e sua desmesura. O cortejo das fantasias sádicas, expressas numa linguagem de órgãos, invade a cena analítica. Ela enfoca alternada e simultaneamente os processos evolutivos e as complexidades do funcionamento psíquico; em seu pensamento as dimensões histórica, dinâmica e estrutural estão sempre imbricadas. A questão da temporalidade não se restringe a uma teoria - original - sobre o desenvolvimento. Klein aborda o "infantil atemporal”, perturbador, mas reserva vital para o ser humano, fundamento de seu idioma arcaico, precioso recurso do analista para o trabalho na contratransferência.

Essencialmente freudiana: assim Melanie Klein sempre apresentou sua técnica, afirmando ter apenas ampliado seu alcance, sem alterar seus fundamentos. Ela criou a técnica para a análise de crianças, possibilidade aberta por seu grande insight ao dar ao brincar da criança o mesmo estatuto que as associações livres do adulto; e estendeu o campo da clínica psicanalítica aos chamados pacientes difíceis. Os autores consideram que essa “profissão de fé freudiana” não é mero jogo de cena, mas ressaltam que Klein imprimiu marcas tão substanciais à psicanálise que pode-se afirmar que trouxe transformações ao campo da clínica psicanalítica. 
R E V I S T A

A proposta clínica kleiniana seria a de permitir que, por meio do contato com a realidade psíquica - com seus impulsos, fantasias inconscientes, dores e sofrimentos -, se possa renunciar a certas defesas radicais e encontrar melhores integração, equilíbrio e contato com a realidade externa e com o próprio psiquismo. Mas isso não é simples. As angústias arcaicas estão fora do campo da linguagem, embora já organizadas como fantasias inconscientes. A comunicação se dá muitas vezes por vias pré-verbais, como a da identificação projetiva. Para acolher essas comunicações é necessária intuição clínica instrumentada pela teoria - a intuição, na verdade a capacidade de contato empático com o mundo dos afetos e das representações inconscientes, só terá validade se orientada por uma teoria sobre a vida mental primitiva. $\mathrm{O}$ analista kleiniano deve mover-se orientado por uma espécie de "sensor de angústias", mesmo quando ainda não manifestas. É preciso que seja capaz de ir ao encontro das ansiedades arcaicas, de mobilizá-las e de recebê-las - "em sua mente e em seu corpo”. Para, então, formulá-las em palavras e devolvê-las, abrindo espaço para simbolizações. No trabalho com pacientes neuróticos, muitas vezes o percurso é inverso - as ansiedades aparecem "pelo avesso" - e faz-se necessário trabalhar primeiramente com as defesas, para então acessar a angústia e as fantasias inconscientes que lhe deram origem.

A interpretação visa, desde o começo da análise, os estratos mais profundos da vida psíquica, mas o analista deve manter a atenção à linguagem do paciente, tal como proposto por Freud. É discutida a idéia, expressa por Lacan, de que a intervenção interpretativa kleiniana seria da natureza da colocação de um greffe - um enxerto - no paciente pela palavra do analista. Para os autores, se consideradas a metapsicologia e a técnica em Melanie Klein, a intervenção não pode ser tomada como mera introdução arbitrária de uma prótese no psiquismo do paciente - muitas vezes, esta é a única possibilidade para se dar figurabilidade, nome e passagem para a simbolização ao irrepresentável pulsional, estruturado como fantasia inconsciente. Reconhecem que em alguns momentos Klein pode ter feito intervenções precipitadas ou usado de uma linguagem excessivamente crua, resultando em certa rudeza. O contraponto está na atenção aos movimentos sutis entre analista e paciente durante a sessão, no "monitoramento contínuo dos vínculos e climas afetivos”, que compõem um estilo de clinicar de extrema delicadeza.

$\mathrm{Na}$ transferência como situação total - concepção da transferência em Melanie Klein - mais do que uma narrativa, o paciente trará à análise a reedição de experiências e relações de objeto, de angústias primitivas e suas defesas correspondentes. O fenômeno transferencial ganha amplitude e complexidade e o analista, esse "personagem enigmático e propiciador de muitas projeções”, em 
maior ou menor grau se deixará levar para o lugar ou papel em que o paciente o supõe, ou mesmo, em certa medida, o encarnará. A análise kleiniana exige uma forte implicação afetiva do analista, mas sem que este ceda a qualquer recurso que não os da escuta e interpretação. Certamente existem riscos. A intuição pode equivocar-se, a interpretação pode ser intrusiva ou mesmo produzir sugestão a clínica pode tornar-se lugar de projeções do analista. O melhor antídoto para tais riscos não estará na evitação desta proximidade ousada com o primitivo quase sem palavra, mas sim na tradicional recomendação de Freud: a análise do analista.

A análise kleiniana é apresentada como um grande embaraço, no qual é preciso entrar para se poder sair, transformado pelo trabalho analítico. De certa forma, a análise é uma longa preparação para o seu próprio término, isto é, para uma separação - separação e perda, movimentos inerentes ao viver, encruzilhadas do desenvolvimento para as quais Klein tanto se voltou. No seu projeto terapêutico o alvo da cura analítica seria o atravessamento da posição depressiva e a solução do complexo edipiano, ou seja, alcançar a capacidade de experimentar relações complexas e ambivalentes com objetos dotados de autonomia. Chega-se também a uma solidão inevitável, condição necessária para certas experiências psíquicas, como o luto. A vida pulsional fica mais integrada ao ego; as urgências do id e as injunções do superego podem então estar articuladas em uma dinâmica flexível e moderadora. Após essa trajetória, adquirem-se as condições para a superação dos padrões narcisistas de relacionamento e para a conquista de uma postura ética de aceitação da alteridade.

A introjecão do bom objeto também figura entre os critérios para o término de uma análise. Contudo, Klein não estabelece uma distinção clara entre o objeto parcial bom, facilmente idealizado, e o bom objeto que pode assegurar o equilíbrio psíquico de quem atravessou a posição depressiva. Em busca de uma discriminação mais refinada, Elisa Ulhoa Cintra e Luis Cláudio Figueiredo propõem que este objeto - que capacita o ego a reparar, criar, suportar frustrações, conviver com ambivalências, e pelo qual se pode ter gratidão - seja o vínculo parental. Muitíssimo diferente do objeto compósito da posição esquizoparanóide, a figura combinada dos pais. Esse seria um objeto duplo, cujo caráter inclui tanto a separação entre suas partes como a existência de um vínculo fecundo entre elas, do qual cada sujeito está excluído. A constituição de um psiquismo forte e rico implica a abertura de um espaço para as alteridades na própria vida intrapsíquica. Nas palavras dos autores,

Não se trata apenas de introjetar a Lei e a interdição, e sujeitar-se à função paterna. Trata-se de internalizar a ligação erótica entre os genitores como possibilidade de estruturação subjetiva e de controle das pulsões destrutivas pelas forças da vida e do amor. É a fonte da criatividade. Mas é também, claro está, uma fonte insuperável da experiência de solidão, pois é de exclusão que se trata. 
$R \quad E \quad V \quad I \quad S \quad T \quad A$

LATINOAMERICANA

DE PSICOPATOLOGIA

F U N D A M E N TA L

ano VII, n. 4, dez/2004

A teoria kleiniana tem implicações nas dimensões social, ética, moral e política do ser humano. Possui um forte componente humanista, a partir das capacidades de reparação, cuidado, consideração pelo outro. As passagens do funcionamento pré-genital, esquizoparanóide, com sua "moralidade primitiva do medo" para a "moralidade madura" do amor, da preocupação e do predomínio da gratidão, alcançada pelo atravessamento da posição depressiva, conduzem à construção de uma responsabilidade autêntica. Embora impregnada de certa esperança, essa posição não é ingênua. Klein se mantém até o final da vida sabedora de que forças destrutivas estarão sempre ameaçando essa condição. Sempre restarão, não integrados pelo ego, algo da crueldade do superego primitivo, da destrutividade não mitigada pela libido; uma cota de angústias inomináveis que escaparam à simbolização. Ciúme, rivalidade, inveja, medo de retaliação - diferentes figurações da ameaça não cessam de se reapresentar. A saúde estará na aceitação dessa natureza, essencialmente dividida, do humano. Que também estará sempre ali, a colocar um limite a qualquer pretensão analítica de uma integração estável e definitiva, e a lembrar que o trabalho elaborativo não cessa.

É interessante como um trabalho em co-autoria possa resultar em uma parceria tão afinada. Rocha Barros encerra sua apresentação ao mesmo com um comentário bem-humorado sobre seu hábito de assinalar as passagens importantes dos textos que estuda - teve que abandonar a prática, para não marcar o livro por inteiro. A tarefa de resenhá-lo foi árdua pela mesma razão. Talvez a mais forte impressão que Melanie Klein. Estilo e pensamento causa ao leitor decorra de seu caráter original, no duplo sentido dessa palavra - original é o novo, mas também significa o retorno à origem.

\section{Referências}

Abram, Jan. A linguagem de Winnicott. Rio de Janeiro: Revinter, 2000. Mahony, P. Freud como Escritor. Rio de Janeiro: Imago, 1992. 